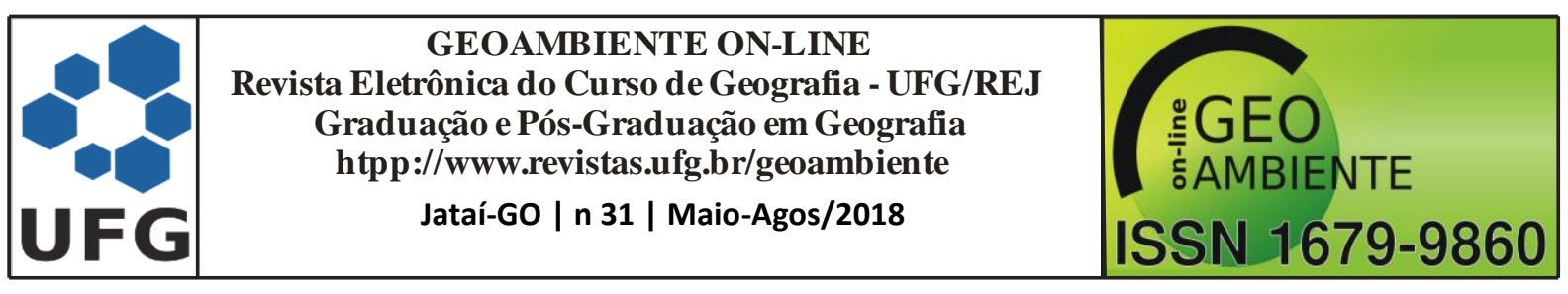

\title{
IMPACTOS SOCIOAMBIENTAIS DA UTILIZAÇÃO DE SISTEMAS AGROFLORESTAIS: O CASO DA FAZENDA OLHO DO CÉU, CHAPADÃO DO CÉU (GO)
}

Jordana Rezende Souza Lima ${ }^{1}$, Mariana Crepaldi de Paula $^{2}$, Hildeu Ferreira da Assunção ${ }^{3}$ $(1$ - Universidade Federal de Goiás, Doutoranda em Geografia - REJ, jojosouzalima@hotmail.com, 2 - Universidade Federal de Goiás, Pós-Doutoranda em Geografia, jatais@gmail.com, 3 - Universidade Federal de Goiás, Professor do Programa de Pós-graduação em Geografia, hildeu@ yahoo.com.br)

Resumo: Diante da expansão da monocultura de grãos e cana no Sudoeste de Goiás e a consequente degradação socioambiental são necessárias novas estratégias de produção benéficas ao ambiente. Objetivo: compreender a influência dos Sistemas Agroflorestais (SAFs) na Fazenda Olho do Céu, município de Chapadão do Céu (GO) com métodos e técnicas da pesquisa qualitativa. Resultados: o plantio de SAF com técnicas de agricultura sintrópica aumenta a cobertura e matéria orgânica do solo, beneficia a retenção de água, abriga um grande número de espécies faunísticas e florísticas, representa uma fonte de dispersão de sementes e de polinizadores, serve como barreira física contra os agrotóxicos e fornece uma produção diversa, orgânica e abundante. O local estudado apresenta condições edáficas, humanas e de mecanização ideais, no entanto há um gargalo na comercialização dos produtos, com algumas perspectivas de solução sendo estudadas ou em vias de implantação.

Palavras-chave: Uso da terra. Conservação do solo. Sustentabilidade. Sistemas Agroflorestais.

\section{SOCIO-ENVIRONMENTAL IMPACTS OF THE USE OF AGROFORESTRY SYSTEMS: THE CASE OF THE FARM OLHO DO CÉU, CHAPADÃO DO CÉU (GO)}

Abstract: Before the expansion of monoculture of grains and sugarcane in the Southwest of Goiás and the consequent socioenvironmental degradation, new production strategies that are beneficial to the environment are necessary. Objective: to understand the influence of Agroforestry Systems (SAFs) on the Olho do Céu Farm, in the county of Chapadão do Céu (GO), using methods and techniques of qualitative research. Results: SAF planting with

\footnotetext{
Artigo recebido para publicação em 27 de Fevereiro de 2018
}

Artigo aprovado para publicação em 09 de Agosto de 2018 


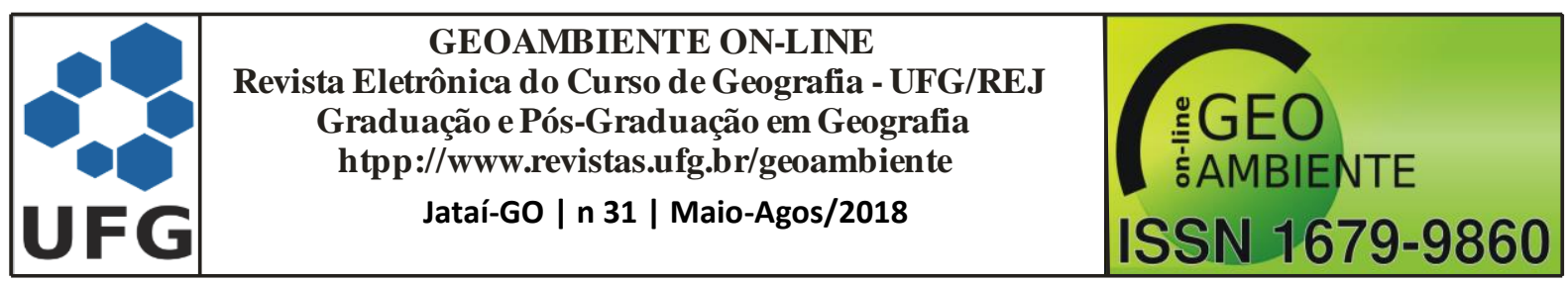

syntropical agriculture techniques increases soil cover and organic matter, benefits water retention, houses a large number of faunal and floristic species, represents a source of seed dispersal and pollinators, serves as a barrier physics against agrochemicals and provides a diverse organic and abundant production. The studied site presents ideal soil, human and mechanization conditions, however there is a bottleneck in the commercialization of the products, with some perspectives of solution being studied or in the process of being implemented.

Keywords: Land use. Soil conservation. Sustainability. Agroforestry Systems.

\section{IMPACTES SOCIOENVIRONNEMENTAUX DE L'UTILISATION DE SYSTÈMES AGRO FORESTIERS POUR RÉCUPÉRATION ENVIRONNEMENTALE: LE CAS DE LA FERME OLHO DO CÉU (GO)}

Résumé : Face à l'expansion de la monoculture de grains et canne à sucre au Sud-ouest de Goiás et la dégradation socio environnementale qui en résulte, sont nécessaires des nouvelles stratégies de production avantageuses à l'environnement. Objectif: comprendre l'influence des Systèmes Agroforestiers (SAFs) dans la Ferme Olho do Céu, ville de Chapadão do Céu (GO) par une recherche qualitative. Résultats: la plantation de SAF aux techniques néguentropiques augmente la couverture et la matière organique du sol, bénéficie la conservation de l'eau, abrite un grand nombre d'espèces (faune et flore), est une source de dispersion de graines et de polinisateurs, sert de barrière physique contre les pesticides et fournit une production diverse, biologique et abondante. Le lieu étudié présente des conditions édaphiques, humaines et de mécanisation idéales, cependant il y a un goulot dans la commercialisation des produits, avec des perspectives de solution étudiées ou en voie d'implantation.

Mots-clés: utilisation des sols. Conservation du Sol. Durabilité. Systèmes Agroforestiers.

\section{INTRODUÇÃO}

A agricultura mecanizada na região Centro-Oeste passou por um processo de expansão desde a década de 60 quando programas governamentais, tais como Programa de Cooperação Nipo-Brasileira de Desenvolvimento dos Cerrados (PRODECER) e Programa de Desenvolvimento dos Cerrados (POLOCENTRO), incentivavam os produtores rurais, e promoveram a capitalização da agricultura (SILVA, 2000). 


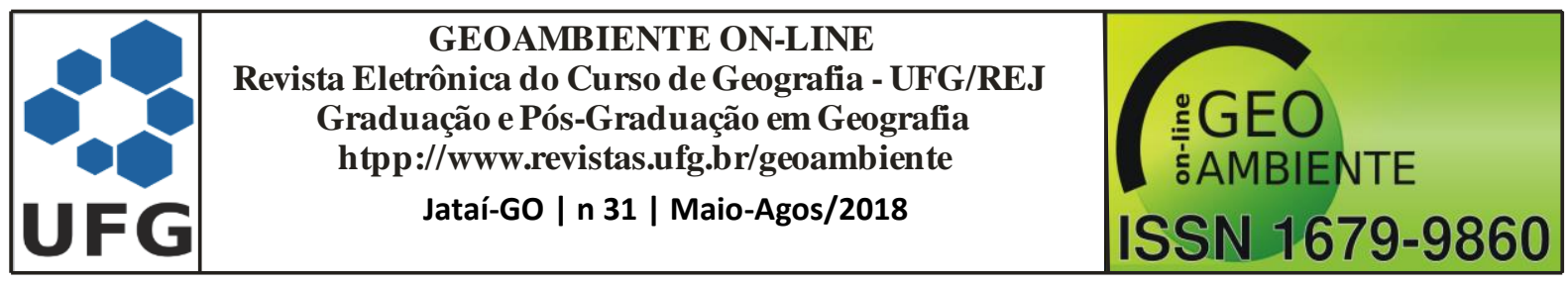

A produção em larga escala só foi possível a partir da mecanização das atividades agrícolas, da tecnologia de ponta e do uso abusivo de insumos agrícolas. Esse processo acarretou diversos problemas ambientais, como diminuição na vazão dos cursos d'água, perda de fertilidade e erosão dos solos, além de mudanças no regime de chuvas, e erosão da biodiversidade do Cerrado (LIMA, 2013).

Atualmente a microrregião Sudoeste de Goiás está inserida na dinâmica do agronegócio, com a produção de grãos e cana destacada no âmbito nacional e internacional (PAULA; OLIVEIRA; RIBEIRO, 2012). Este sistema monopolista de cultivo e manejo da terra provoca a deterioração do ambiente e das pessoas que nele vivem e dele necessitam para a sobrevivência, assim como promove a aculturação da população local, e a concentração de terra e poder nas mãos da minoria.

Ressalta-se a urgência de desenvolver tecnologias de cultivo que visem à saúde humana e a qualidade ambiental. Para tanto, é necessário o estabelecimento de estratégias de ação quanto ao uso dos recursos do Cerrado, mantendo uma avaliação holística, envolvendo tanto os aspectos técnicos, econômicos, sociais, ambientais e políticos.

Diante deste contexto percebe-se que os sistemas de cultivos múltiplos, com princípios agroecológicos, têm alcançado sucesso tanto no que tange aos aspectos ambientais como socioeconômicos. Os sistemas agroflorestais passaram a ser vistos como alternativa promissora para propriedades rurais dos países em desenvolvimento. Pela integração da floresta com culturas agrícolas e com a pecuária, esse sistema oferece uma alternativa que pode minimizar problemas de baixa produtividade, de escassez de alimentos e da degradação ambiental generalizada (ALMEIDA et al, 1995; SANTOS, 2000).

No que diz respeito às questões de proteção do solo, Young (1997) considera que os efeitos do manejo agroflorestal para a manutenção da fertilidade do solo podem ser considerados como um fator direto no controle da erosão, através da proteção fornecida pela cobertura do solo pela serrapilheira do papel das árvores como barreira ao escoamento superficial, suavizando a erosão laminar e da alta concentração de matéria orgânica.

A partir de uma ótica econômica percebe-se que a viabilidade dos sistemas agroflorestais é incrementada em relação aos cultivos tradicionais modernizados. A adoção de sistemas agroflorestais pode promover um fluxo de caixa mais regular aos agricultores e oferece simultaneamente uma variedade de produtos madeireiros e não madeireiros, 


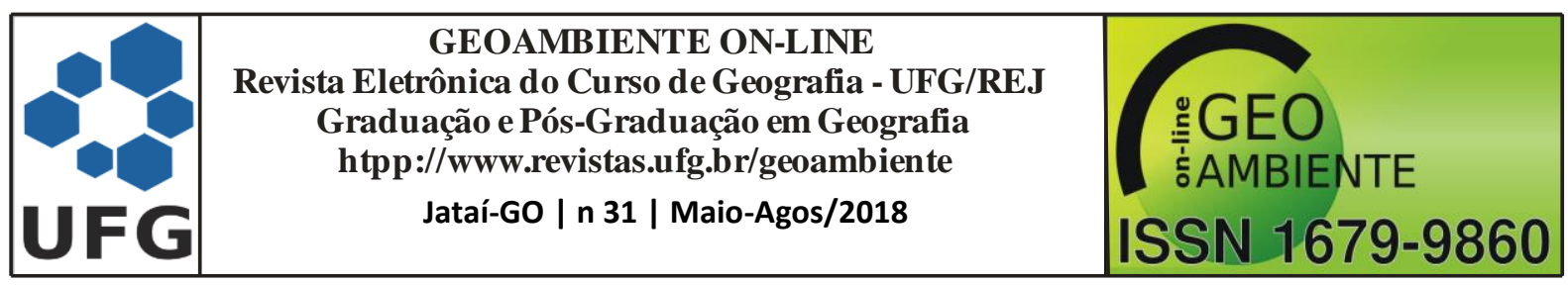

permitindo aos agricultores maior flexibilidade na comercialização e racionalização da mãode-obra familiar (SANTOS, 2000).

Partindo desse ponto de vista justifica-se a necessidade de promover tecnologias dessa magnitude para o setor agrícola, pois trazem o conceito de produção limpa, sem o uso de agrotóxicos, contribuindo para a qualidade ambiental e a saúde humana, e garantindo a segurança alimentar. Para tanto esse estudo tem como objetivo analisar, compreender e promover os benefícios do sistema agroflorestal da Fazenda Olho do Céu, no município de Chapadão do Céu, tanto para a população consumidora dos alimentos produzidos, quanto para os agricultores e o ambiente onde esses sistemas estão inseridos.

\section{FUNDAMENTAÇÃO TEÓRICA}

O campo brasileiro tem sido cada vez mais desnaturalizado e mediado pela técnica, e a natureza encontrada no campo é vista apenas como um recurso que precisa ser aproveitado, que seja pela atividade do turismo rural ou ecológico.

Diante desse tecnicismo e dos muitos progressos da ciência, cujos resultados nem sempre são usados para o bem comum mas sim para a produção, reprodução e para o acúmulo de capital, reflete-se sobre o passado, o presente, e o momento mais crucial, o futuro do homem nesse planeta. É bastante clara a crise agroecológica vivida no presente, e a tendência é seu acirramento.

Mendonça (2005) deixa clara essa situação de crise quando afirma que a qualidade de vida do homem tem apresentado uma queda sem limites nos últimos anos, fato que contradiz tamanho progresso científico. Porém diante da dominação do capital e o incentivo ao consumismo, preocupam-se apenas com a quantidade do que é produzido, abdicando da qualidade dessa produção.

"Contrariando as promessas de desenvolvimento virtuoso impulsionadas pela economia do agronegócio, as regiões de expansão das monoculturas e dos grandes criatórios caracterizam-se por reproduzir estilos de crescimento econômico fortemente concentradores de renda" (PETERSEN, 2017). É nítido que para buscar soluções para essa crise ecológica associada às demais crises, sejam econômicas ou sociais, é preciso repensar o modo de produção atual. 


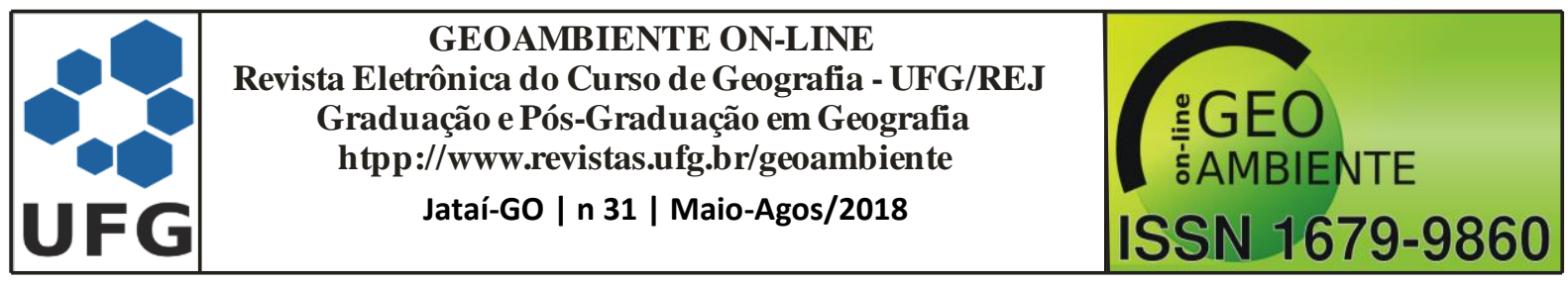

O Brasil é um dos países com maior concentração fundiária do mundo, onde $76 \%$ das terras agricultáveis estão sob um modelo de produção agroindustrial, o restante das terras (24\%) abriga $84 \%$ dos proprietários rurais, agricultores familiares que se dedicam a produzir alimentos, ou seja, injustamente, vê-se que nesses $24 \%$ de terras, camponeses e agricultores familiares alimentam 70\% da população (TOLEDO; BARRERA-BASSOLS, 2015).

Diferentemente da mentalidade agroindustrial que vê os produtores como receptores e replicantes do conhecimento científico moderno, a agroecologia reconhece e valoriza as experiências dos produtores locais, especialmente daqueles com uma longa presença histórica, sendo assim o diálogo de saberes torna-se o princípio fundamental da pesquisa agroecológica (TOLEDO; BARRERA-BASSOLS, 2015).

A agroecologia oferece conhecimentos e metodologias necessárias para desenvolver uma agricultura que seja, por um lado, ambientalmente adequada e, por outro, altamente produtiva, socialmente equitativa e economicamente viável. É possível produzir integrando os componentes de cada sistema de maneira que se possa aumentar a eficiência biológica, preservar a biodiversidade, manter ou aumentar a capacidade produtiva e de auto-regulação do agroecossistema. Os princípios da agroecologia buscam poupar insumos e reduzir custos e riscos, se adequar em zonas mais frágeis, ser congruentes com os sistemas agrícolas, cultura e modos de vida dos agricultores, assim como melhorar a segurança alimentar e nutricional, a saúde e o ambiente (ALTIERI, 2006).

Os sistemas agroflorestais em sucessão de espécies e em sintropia, representam nada mais do que o funcionamento da própria natureza, entretanto é um agroecossistema, pois, simultaneamente produz alimento, água e solo vivo e saudável, contribuindo com a conservação ambiental. Na maior parte da história da humanidade sempre se produziu imitando o processo natural, baseando-se no reconhecimento, aproveitamento e na criação de diversidade, atuando em sintonia e não em conflito com as leis naturais (TOLEDO; BARRERA-BASSOLS, 2015).

Para Gotsch (1997, p.5) a agricultura sintrópica se resume a uma "tentativa culta de conseguir o necessário daquilo que precisamos para nos alimentarmos, além das outras matérias primas essenciais para nossa vida, sem a necessidade de diminuir e empobrecer a vida no lugar, na terra", considerando um consumo mínimo de energia, extinguindo o uso de 


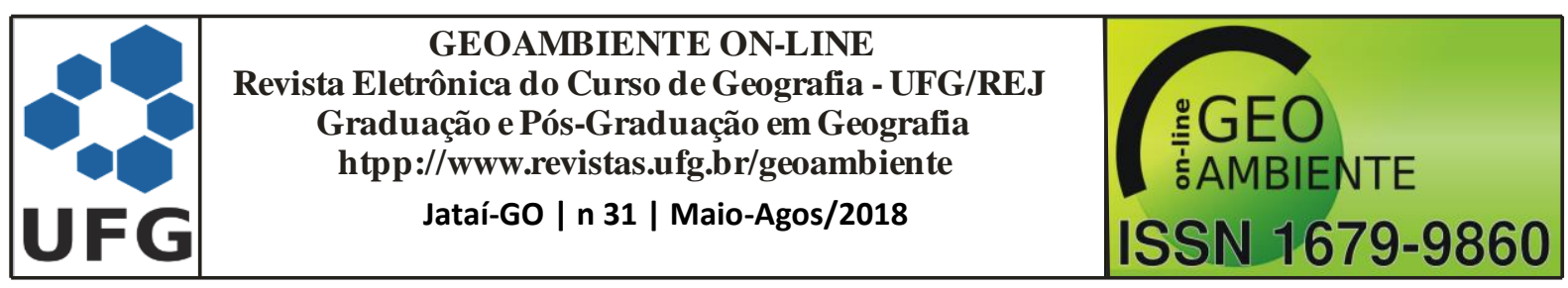

maquinários pesados, agrotóxicos ou fertilizantes químicos, assim como outros adubos externos ao próprio sistema.

A agricultura familiar precisa ser revitalizada, pois sua essência é camponesa, além de outros fatores gerais que podem ser destacados, tais como representar a chave para a segurança alimentar local e mundial; essas pequenas propriedades colaboram com o resfriamento do clima pois conservam mais os recursos naturais e aumentam o sequestro de carbono pelos solos; sendo diversificadas representam modelos de sustentabilidade; são livres de organismos geneticamente modificados (OMGs), ou seja, são agrobiodiversos (ALTIERI, 2012).

Faz-se necessário manter e enriquecer o patrimônio biocultural e a conservação de sistemas de produção tradicionais representa um caminho apropriado para a manutenção dessa diversidade genética e paisagística local, além de serem um direito social e individual fundamental (TOLEDO; BARRERA-BASSOLS, 2015).

\section{MATERIAIS E MÉTODOS}

Área de estudo

A Fazenda Olho do Céu está localizada no município de Chapadão do Céu (GO), o qual faz parte da microrregião Sudoeste de Goiás, conforme as coordenadas geográficas: $18^{\circ}$ 22’25” S e 52³7'43” W (Figura 1).

Figura 1- Localização da área de estudo: Fazenda Olho do Céu, município de Chapadão do Céu (GO).

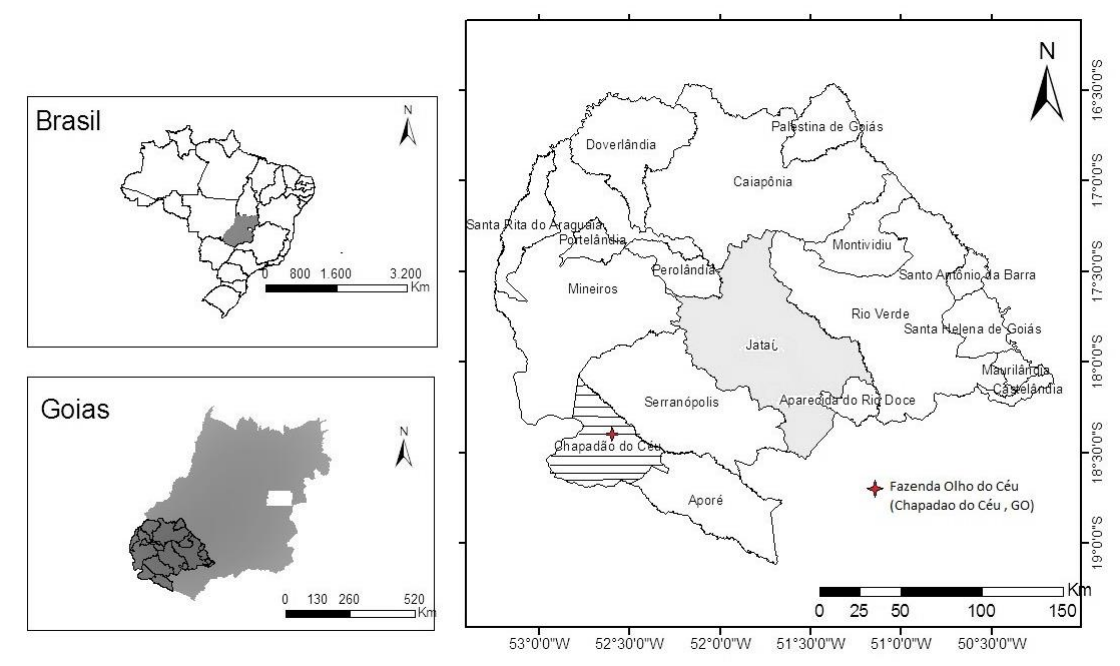

Fonte: SIEG, 2016. 


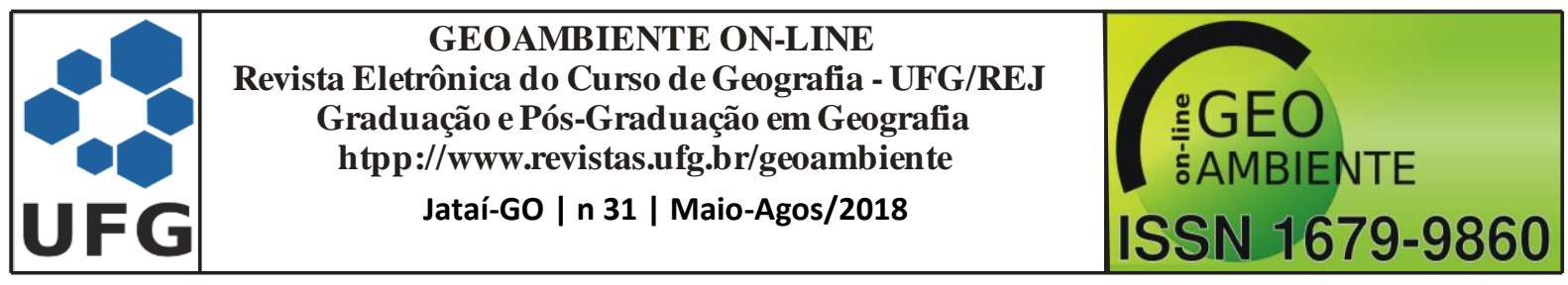

A propriedade, situada às margens do rio Formoso, abrange no total 420 hectares, sendo que 4 ha são destinados aos SAFs, 100 ha são destinados à reservas e APP, 16 ha são pastagens cultivadas, e o restante são destinadas ao cultivo de soja (Figura 2).

Figura 2- Vista aérea da Fazenda Olho do Céu, município de Chapadão do Céu (GO).

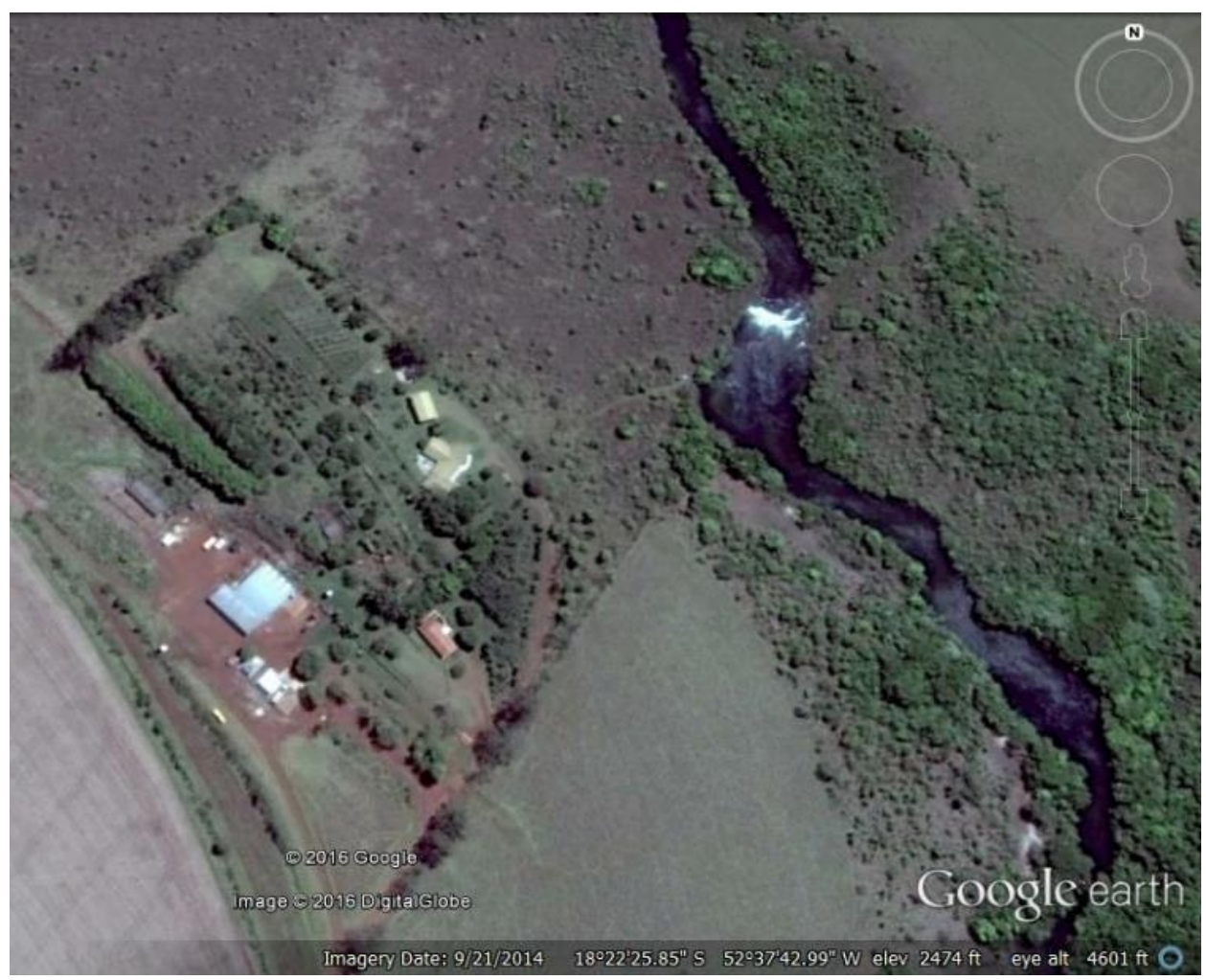

Fonte: Gogle Earth, 2016.

As lavouras temporárias representam a atividade econômica predominante no município de Chapadão do Céu (GO), representando cerca de $60 \%$ de sua área total, a qual totaliza 218.513ha. O município ainda abriga, aproximadamente, em 10\% de seu território parte do Parque Nacional das Emas. Os estabelecimentos agropecuários ocupam 131.092 hectares do município, desses 106.584 hectares são cultivadas com lavouras temporárias. No ranking de produção de soja, Chapadão do Céu ocupa o sétimo lugar, no estado (IBGE, 2018).

\section{Métodos e técnicas}




\begin{tabular}{|c|c|c|}
\hline & $\begin{array}{c}\text { GEOAMBIENTE ON-LINE } \\
\text { Revista Eletrônica do Curso de Geografia - UFG/REJ } \\
\text { Graduação e Pós-Graduação em Geografia } \\
\text { htpp://www.revistas.ufg.br/geoambiente } \\
\text { Jataí-Go | n } 31 \text { | Maio-Agos/2018 }\end{array}$ & $\begin{array}{c}\text { : GEO } \\
\text { G.AMBIENTE } \\
\text { G }\end{array}$ \\
\hline
\end{tabular}

A pesquisa em si está intimamente relacionada à necessidade de buscar conhecimento. $\mathrm{O}$ ato de conhecer é o processo de interação efetuado entre o indivíduo e a realidade, o qual permite descobrir a sua forma de ser ou pelo menos, adquirir respostas provisórias para um problema definido. As soluções para esses problemas seriam, então, o conhecimento (SEABRA, 2001).

A pesquisa qualitativa ocupa um reconhecido lugar entre as várias possibilidades de se estudar os fenômenos que envolvem os seres humanos e suas intrincadas relações sociais, estabelecidas em diversos ambientes (GODOY, 1995).

Este estudo foi desenvolvido baseado em métodos e técnicas da pesquisa qualitativa com o intuito de compreender a influência dos Sistemas Agroflorestais (SAFs) desenvolvidos na Fazenda Olho do Céu, no município de Chapadão do Céu. Optou-se por analisar os SAFs desenvolvidos nessa propriedade pelo fato de que a mesma também é utilizada como área demonstrativa e de formação. O proprietário da fazenda recebe estudantes de todos os cursos da UFG e outras universidades da região, por exemplo, estudantes de Agroecologia da FIMES, no intuito de complementar a formação teórica em agroecologia, sistemas agroflorestais e permacultura, além de contribuir com a formação de pequenos agricultores da região.

Realizou-se um levantamento sobre a propriedade e suas características junto ao proprietário da mesma, em forma de entrevista não estruturada, pois pesquisas desse tipo caracterizam-se pela interrogação direta das pessoas cujo comportamento se deseja conhecer. Entre as principais vantagens de se realizar um levantamento, destaca-se o conhecimento direto da realidade, pois à medida que as próprias pessoas informam acerca de seu comportamento, crenças e opiniões, a investigação torna-se mais livre de interpretações calcadas na subjetividade dos pesquisadores. Outra vantagem está na economia e rapidez desse método, pois quando os dados são obtidos por meio de entrevistas e questionários, os custos tornam-se relativamente baixos (GIL, 2010).

Após a entrevista realizada com o proprietário da área, realizou-se uma visita guiada nas áreas de SAFs, onde foram feitas as observações diretas e o registro fotográfico. Aproveitou-se para acompanhar o plantio de uma nova área, na qual estudantes de graduação da Universidade Federal de Goiás colaboravam com a implantação, e buscavam aprender mais sobre esse tipo de cultivo e seus manejos. 


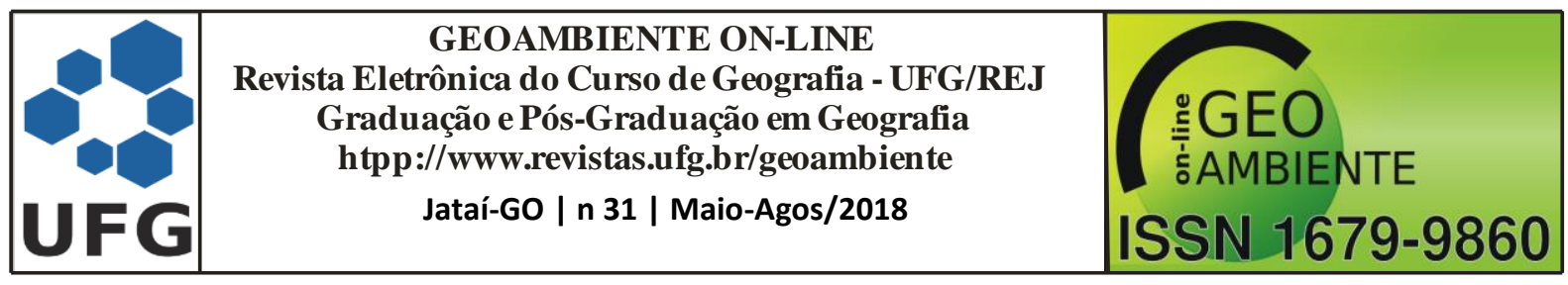

A visita guiada, nomeada também como turnê guiada, consiste em uma técnica baseada na observação e registro livre dos fenômenos observados em campo. Durante os percursos também foram realizadas entrevistas com o proprietário. Apesar de parecer um processo simples e ser uma das formas mais básicas de obtenção de dados, envolve muitas sutilezas e detalhes que devem estar sob o controle do pesquisador (ALBUQUERQUE et al, 2008).

\section{RESULTADOS E DISCUSSÃO}

Estes sistemas agroflorestais são sistemas que se baseiam no cultivo de forma a respeitar as características sucessionais das espécies. Os aspectos principais dos sistemas agroflorestais estão na presença deliberada de componentes florestais para fins de produção, de proteção ou visando a ambas as situações simultaneamente (PASSOS; COUTO, 1997).

$\mathrm{Na}$ área estudada se utilizam os princípios de Agrofloresta Sucessional e Agricultura Sintrópica, desenvolvidos pelo pesquisador suíço Ernst Götsch. Estes princípios procuram levar em conta a ecologia das espécies no que se refere às suas necessidades edáficas e disposição em suas áreas de ocorrência natural, assim como os princípios de sucessão natural, para otimizar a implantação dos sistemas. Outra especificidade deste sistema é a utilização abundante de matéria orgânica (MO) para cobertura do solo. O agricultor reaproveita os resíduos oriundos das podas da cidade, os quais são triturados na fazenda por meio de implemento próprio; bem como o bagaço de cana e casca de algodão que são cultivados nos arredores da cidade.

O reaproveitamento de matéria orgânica que seria desprezada representa uma economia tanto para o ambiente, mas principalmente para o agricultor familiar. A matéria orgânica é uma rica fonte de nutrientes necessários para a produção de alimentos, além do seu uso ser sustentável, ele dispensa o consumo de insumos industrializados, e contribui para a cobertura do solo, consequentemente, sem a exposição do mesmo, se reduz significativamente o processo de erosão laminar.

No acompanhamento da implantação de uma pequena área demonstrativa (aproximadamente $7 \mathrm{~m}$ X 20m), onde as espécies foram selecionadas de acordo com suas finalidades, espécies cultivadas para a produção de matéria orgânica (MO), frutas e madeira, tais como banana, mamão, manga e eucalipto, bem como espécies para a produção de 


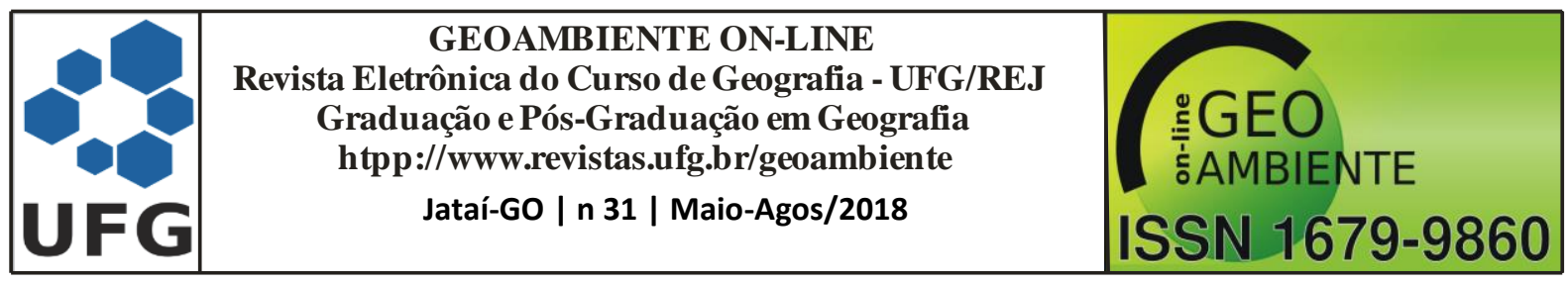

alimentos, a saber: alface, brócolis, couve flor, repolho, couve, salsa, cebolinha, rúcula, inhame, batata doce, mandioca, abacaxi, café, abacate, frutas cítricas, cenoura, rabanete. O abacaxi também é cultivado para promover a recuperação do solo, em áreas degradadas.

O uso de exóticas, tais como o eucalipto e a banana, nos sistemas agroflorestais é vantajoso pois a legislação é mais flexível para o manejo e corte. O eucalipto, dada sua eficiência fotossintética, é um excelente produtor de matéria orgânica, fornecendo biomassa durante seu crescimento. A peculiaridade no uso do eucalipto neste tipo de cultivo se dá pelas podas frequentes para utilização de Matéria Orgânica, o que não ocorre nos monocultivos ou nas associações agroflorestais simples. A característica de rebrota do eucalipto garante um fornecimento de MO constante que, aliado à bananeira, garante o fornecimento de nutrientes do SAF e a cobertura do solo. A parte que não é podada fornece fustes de madeira aos 7 anos.

A preparação do solo, é feita com o calcário e o pó de rocha, para posterior implantação dos sistemas. Em alguns locais a isca para formiga é utilizada, controle que é aceito na agricultura orgânica. Nas covas é adicionado Iorin e farinha de osso como adubos (Figura 3).

Figura 3- Adubação das covas dos SAFs com Iorin e farinha de osso, Fazenda Olho do Céu, município de Chapadão do Céu (GO).

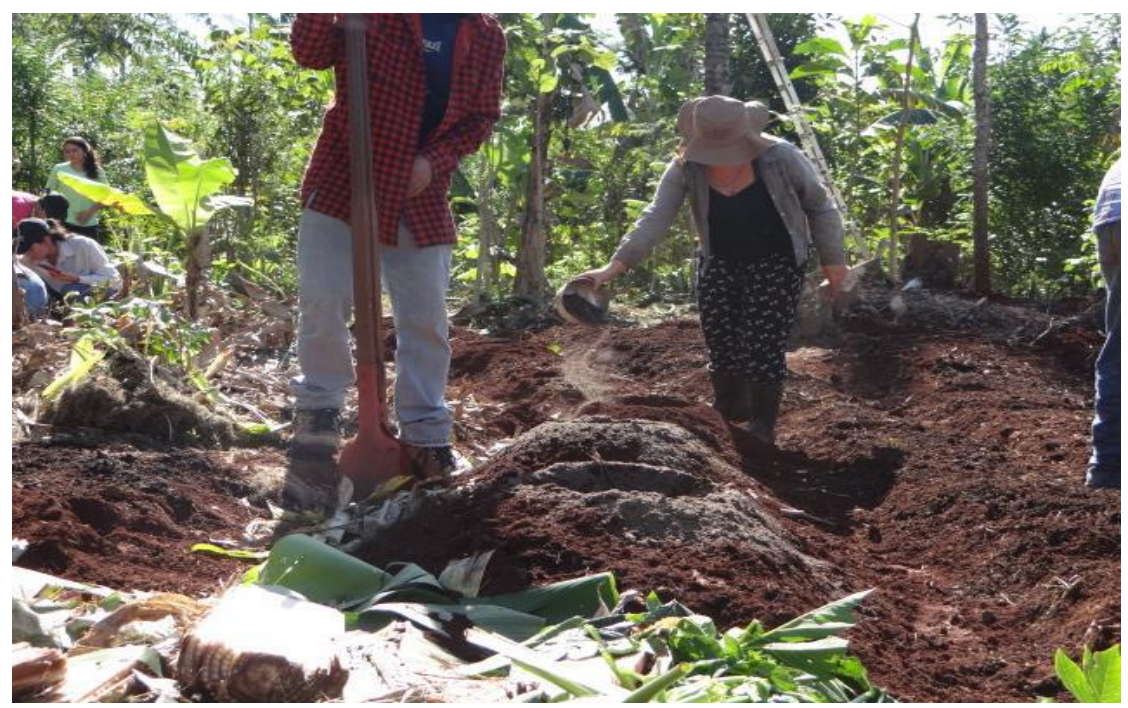

Fonte: Próprio autores

A cultura da abundância predomina nesse sistema tanto em MO, quanto na hora da colheita, pois tudo é aproveitado, toda a produção que não é utilizada para o consumo é 


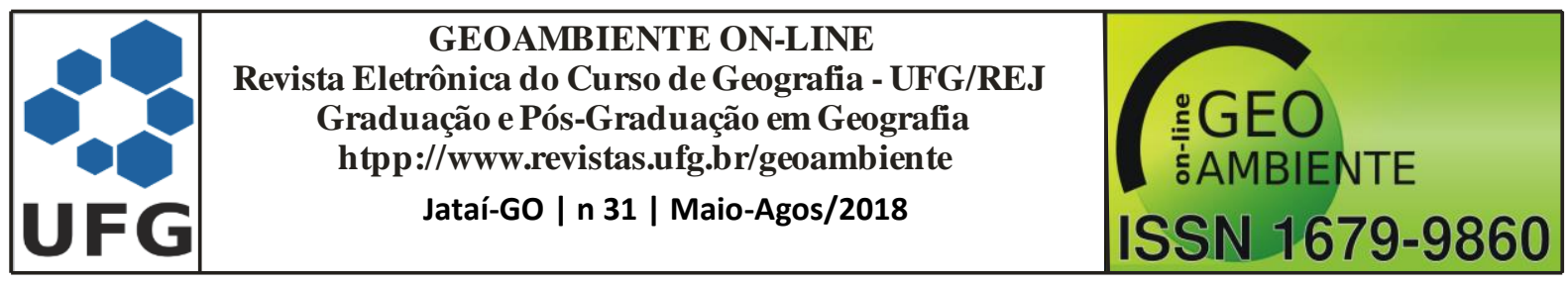

devolvida ao solo para sua cobertura e adubação, não o deixando exposto em nenhum momento, o que beneficia a ciclagem de nutrientes e evita o processo de erosão laminar (Figura 4).

Figura 4- Adubação orgânica do solo, Fazenda Olho do Céu, Chapadão do Céu (GO).

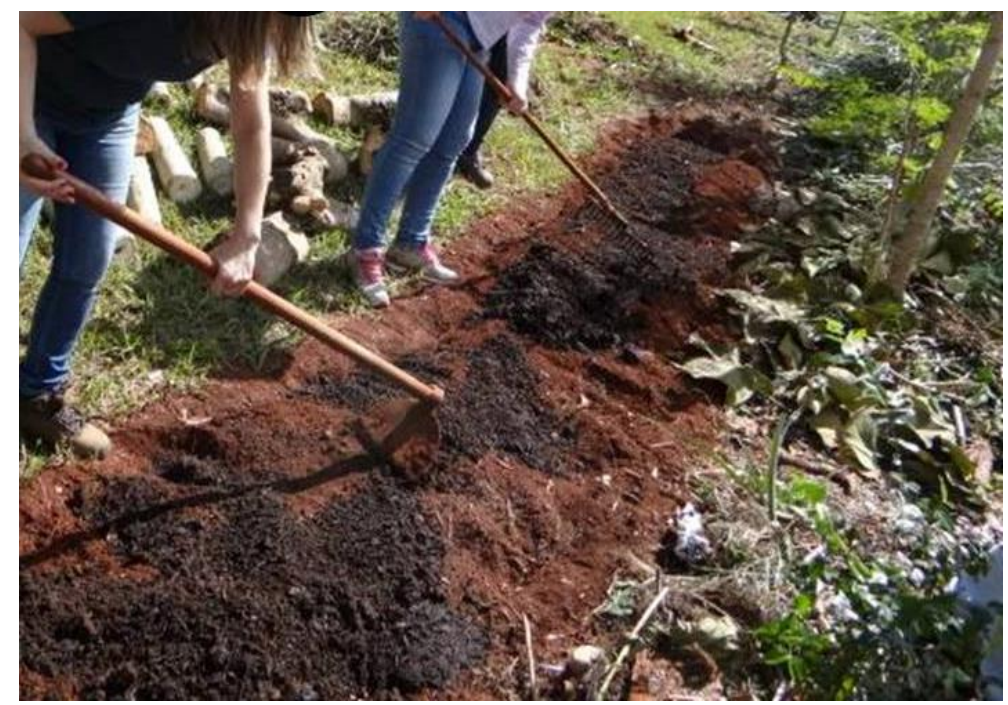

Fonte: Próprio autores

De acordo com a pedologia $($ pedon $=$ solo + logia $=$ estudo), solo é a coleção de corpos naturais dinâmicos, que contém matéria viva e é resultante da ação do clima e da biosfera sobre a rocha, cuja transformação em solo se realiza durante certo tempo e é influenciada pelo tipo de relevo (LEPSCH, 2002). A MO incorporada ao solo se decompõe, fazendo com que o solo cresça $1 \mathrm{~cm} / \mathrm{ano}$ em MO decomposta incorporada e aumentando a quantidade de microorganismos no solo. Como o solo não fica exposto, a retenção de água é garantida e potencializada, abastecendo o lençol freático da região, o que propicia uma maior disponibilidade de água para outros agricultores e para a população da região.

Verificou-se que o cultivo em forma de SAFs tem promovido a recuperação do solo e do ambiente, trazendo uma proposta diferente para a recuperação de bioma. Entre as vantagens desse sistema percebe-se que abriga um grande número de espécies faunísticas e florísticas, pois o alimento disponível em todo momento também beneficia a fauna da chamada zona de amortecimento. O sistema passou a representar uma fonte de dispersão de sementes e de polinizadores. Como a produção predominante no município é a monocultura 


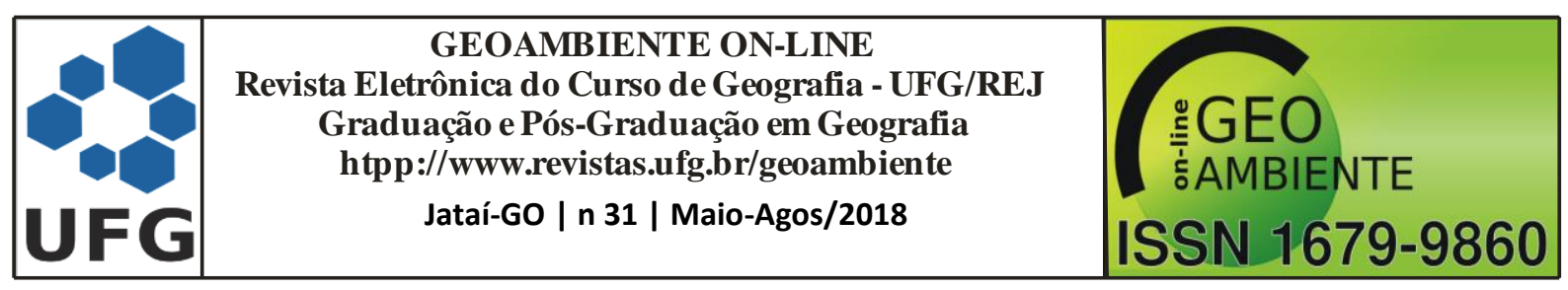

da soja, o uso de agrotóxicos é intensivo, logo os SAFs ainda servem de proteção local, como barreiras físicas contra os insumos utilizados nas lavouras que cercam a fazenda.

O plantio de SAFs, que iniciaram em 2011 em um pequeno espaço da fazenda, hoje ocupa 4 hectares da área total da propriedade (Figura 5). Os SAFs têm se expandido para as áreas de plantio de soja, pois os agricultores verificaram que essa forma de cultivo é mais produtiva e mais adequada à filosofia da família, que se preocupa com a melhor forma de manejar a terra, mitigando os danos ao ambiente.

Figura 5 - Paisagem no interior da primeira área de SAF em 2011 na propriedade.

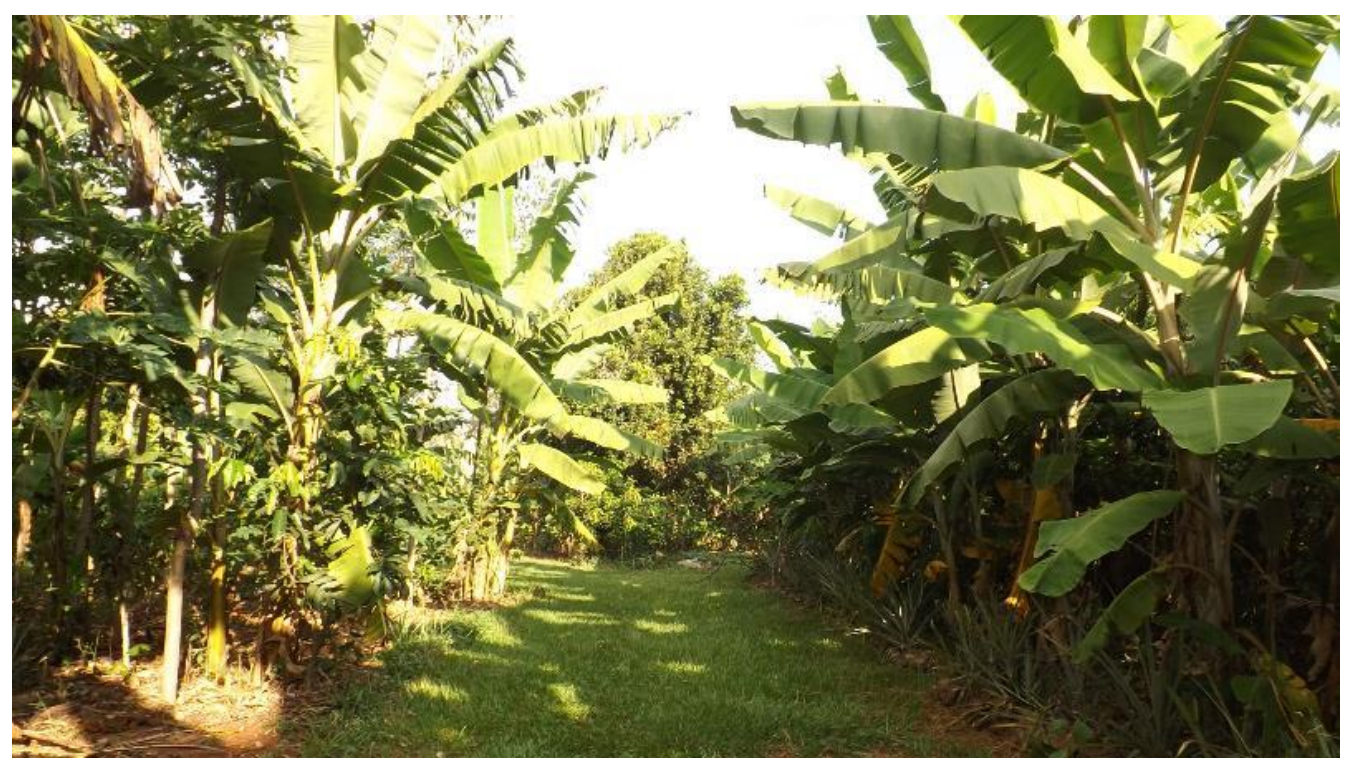

Fonte: Próprio autores

O crescimento desta atividade encontrou um obstáculo nas dificuldades de comercialização. Atualmente toda a produção é consumida pelos trabalhadores das fazendas da família (cerca de 20 pessoas) e comercializada na feira da cidade de Chapadão do Céu. Os desafios encontrados pelo produtor são a baixa demanda local por alimentos orgânicos ou oriundos de uma agricultura menos agressiva ambientalmente. Assim, o produtor avalia que as próximas implantações serão menos voltadas à horticultura e mais ao café ou mesmo a um sistema silvopastoril.

Vários cursos do Centro Universitário de Mineiros (UNIFIMES), Universidade Federal de Goiás - Regional Jataí (UFG), e o Núcleo de Pesquisa e Extensão em Agricultura Familiar (NEAF) mantém estreita relação com a fazenda, que recebe grupos para formações e 


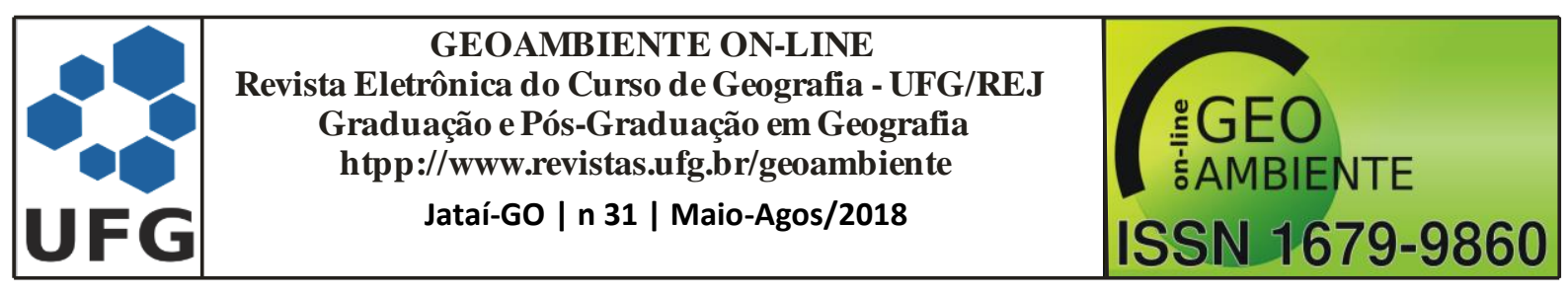

cujos trabalhadores auxiliam em projetos, formações e encontros do NEAF periodicamente. Esta troca constante cria um ambiente dinâmico e aumenta as trocas de experiências, assim como contribui para a divulgação dos trabalhos desenvolvidos.

As condições de produção são ideais: a área possibilita a mecanização, tem água disponível em abundância e o agricultor passou por diversas formações em agricultura sintrópica no Brasil. Na fazenda utiliza-se para o manejo do sistema alguns implementos, tais como furador de cova, picador, e tobata, entre outros (Figura 6).

Figura 6- Implementos utilizados na Fazenda Olho do Céu: a) furador de cova; b) picador.
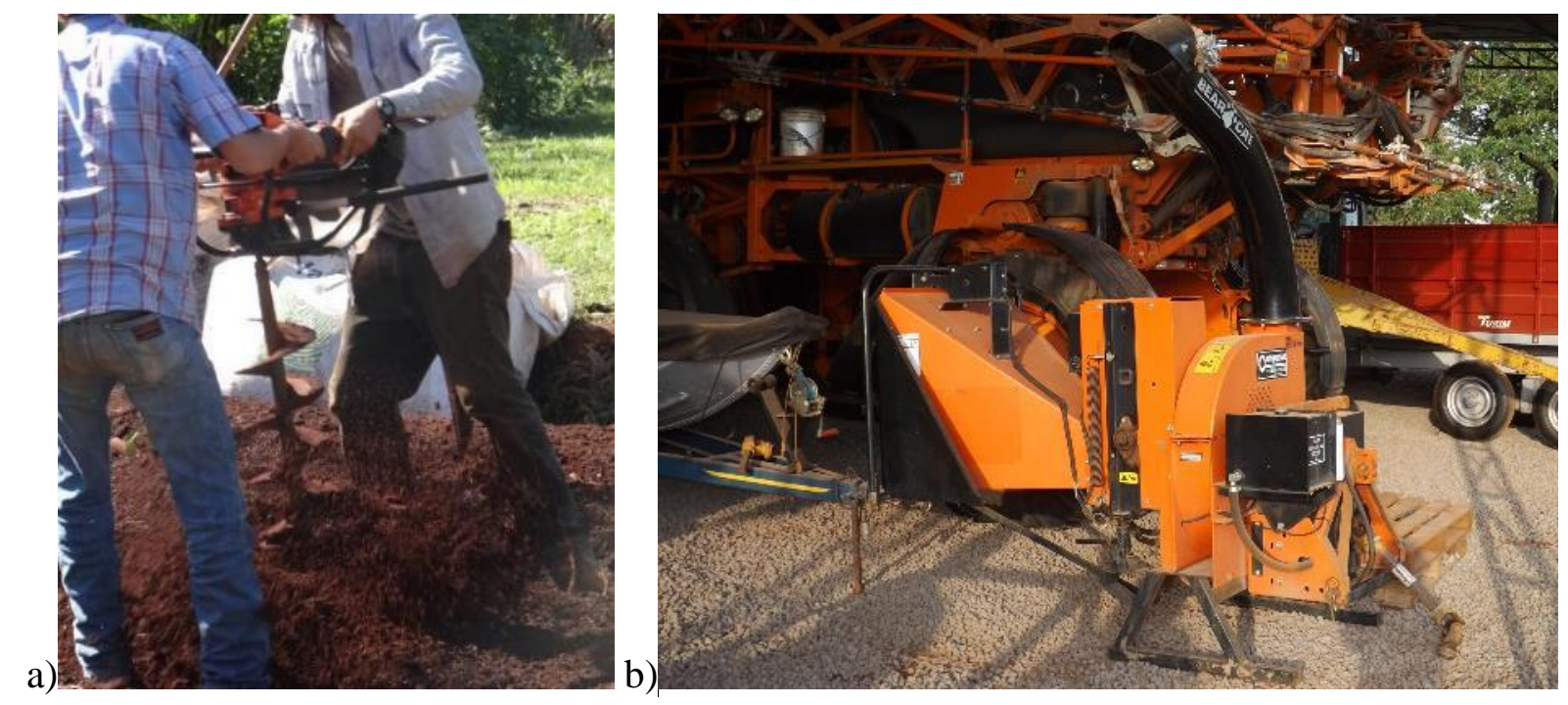

Fonte: Próprio autores

Como sistema de irrigação, é utilizado o modo de gotejo e/ou aspersão, os quais garantem a manutenção da umidade do solo propícia ao desenvolvimento das culturas em consórcio, e também realiza-se a adubação verde do solo. Não se utiliza nenhum insumo industrializado na produção dos SAFs, apenas a isca para formiga, que é permitida na legislação brasileira que rege a produção orgânica. Opta-se, quando necessário, por caldas naturais, e o controle manual, para manter a sanidade vegetal. Os produtos fitossanitários utilizados nas culturas temporárias são armazenados em local adequado, as embalagens são devolvidas, cumprindo a legislação pertinente.

Sobre a salubridade rural, o agricultor afirma que os gatos são parceiros no controle de ratos e baratas. E quanto ao uso de plantas medicinais no cotidiano, afirma que a 


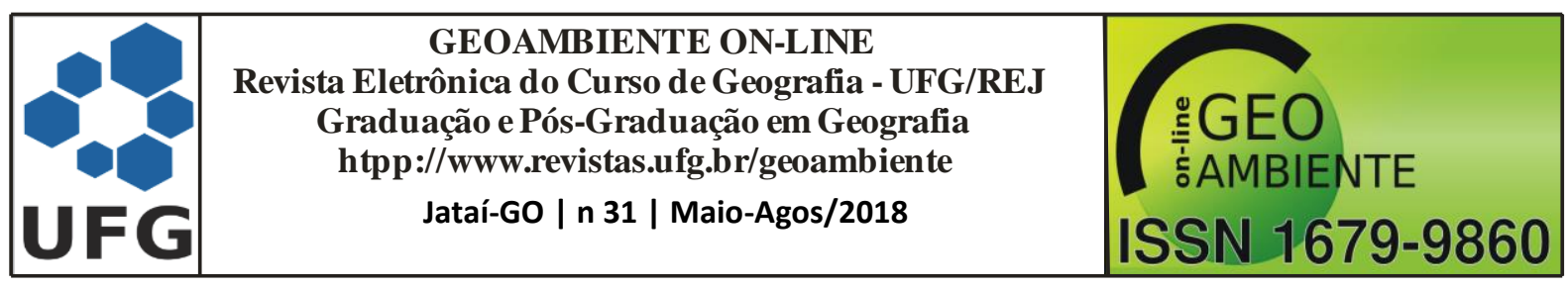

frequência é alta, e a origem das mesmas é o próprio quintal. Os equipamentos de proteção individual, também são utilizados para o trabalho diário. Quanto aos resíduos gerados na propriedade, constatou-se que os banheiros são ecológicos, os resíduos domésticos gerados na cozinha são compostados em pilha ao ar livre, para serem usados posteriormente nos SAFs; e os resíduos sólidos não aproveitáveis são coletados.

Está em fase de finalização, a construção de uma casa para alojar estudantes e agricultores, os quais se interessem em trabalhar voluntariamente para apreender a produzir sistemas agroflorestais. O abastecimento de água vem canalizado de uma nascente próxima, é aproveitado para a irrigação dos SAFs. O sistema de esgoto da casa é ecológico, baseados em técnicas da bioconstrução e da permacultura (Figura 7).

Figura 7 - Construção de alojamento para estudantes e agricultores na propriedade: a) água para o abastecimento do alojamento e aproveitada para irrigação; b) fossa ecológica; c) casa para alojamento.

a)

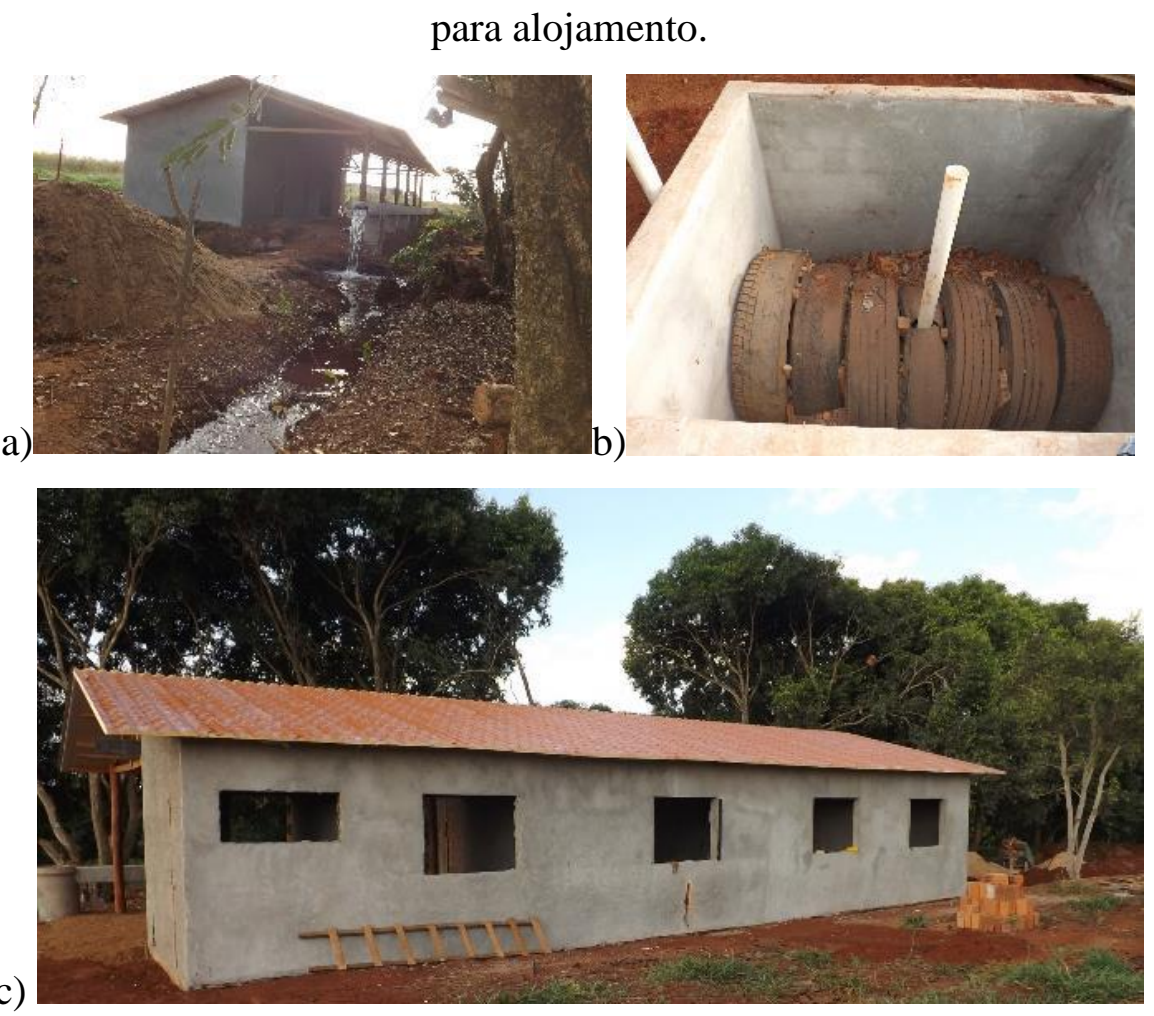

Fonte: Próprio autores

A motivação do agricultor e sua família, juntamente com estas condições ideais, tem garantido uma produção de alta qualidade com pouco investimento em mão de obra, pois em 


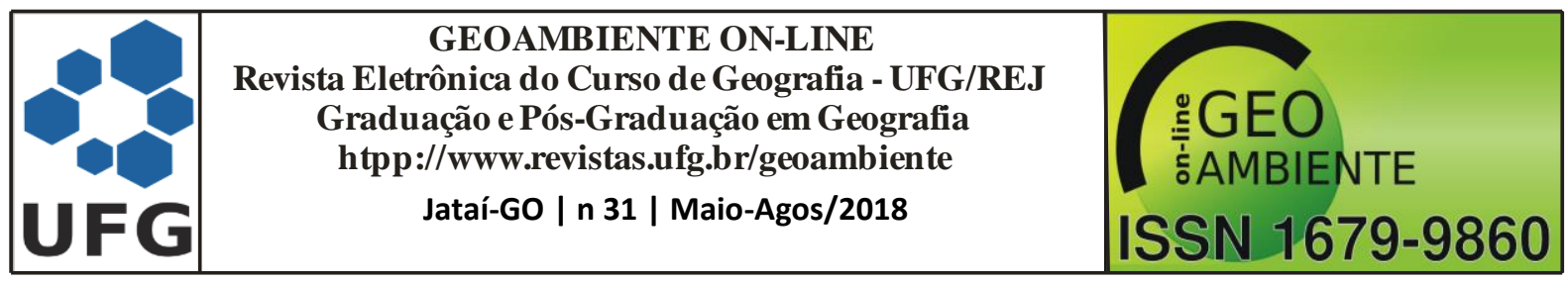

média, duas pessoas trabalham no local, em forma de parceria. A distância da cidade não dificulta o escoamento da produção, pois a propriedade situa a $5 \mathrm{~km}$ de Chapadão do Céu (GO).

A produção de soja alcançou 68 sacas/hectare e de milho 120 sacas/hectare na última safra e entressafra. A produção agroflorestal já em comercialização abrange as seguintes variedades: cana de açúcar, mandioca, batata, inhame, banana, abacaxi, laranja, mamão, abacate, gengibre, açafrão, amora, urucum, taioba, abóboras, berinjela, pimentão e hortaliças (couve, alface, coentro, rúcula, salsa, e cebolinha verde). Outras variedades que são cultivadas, mas não são comercializadas, ou por não estar em fase de produção, ou por serem utilizadas apenas para consumo, ou ainda para produção de matéria orgânica: café, cará do ar, limão, eucalipto, e nativas do cerrado. É importante ressaltar que essa comercialização é destinada direto ao consumidor, por meio de feiras livres e comercio solidário em redes, valorizando quem produz e quem consome. A produção animal e derivados (aves e ovos) é restrita ao consumo próprio. Os dejetos dos animais são utilizados como adubo nos SAFs.

Os proprietários também procuram minimizar os impactos no cultivo da soja aplicando um biofertilizante, produzido a própria fazenda, à base de rúmen de vacas a fim de aumentar a presença de microorganismos no solo. De fato, as áreas pulverizadas possuem maior presença de microorganismos, o que se reflete na qualidade do grão. Porém o sistema de monocultivo não permite um acúmulo significativo de matéria orgânica no solo, o que inviabiliza a resiliência do processo, o qual deve ser repetido a cada plantio.

\section{CONSIDERAÇÕES FINAIS}

Diante da crise ambiental e econômica que o mundo vive, o modo de produção deve ser repensado. Uma produção monocultora e em larga escala, além de não representar produção de alimento, mas sim produção e reprodução de capital, não leva em consideração o seu custo entrópico. Quanto mais se reduz a diversidade em um ecossistema mais desequilíbrio é gerado, ou seja, maior entropia. O atual modelo de produção, resulta em um acúmulo desnecessário de riquezas nas mãos de poucos, às custas da fome e miséria de muitos, e esse cenário indica um colapso do atual sistema e da humanidade.

Deve-se considerar o planeta como referência desse custo entrópico, pois se a garantia de sobrevivência das sociedades futuras precisa ser um dos principais objetivos do 


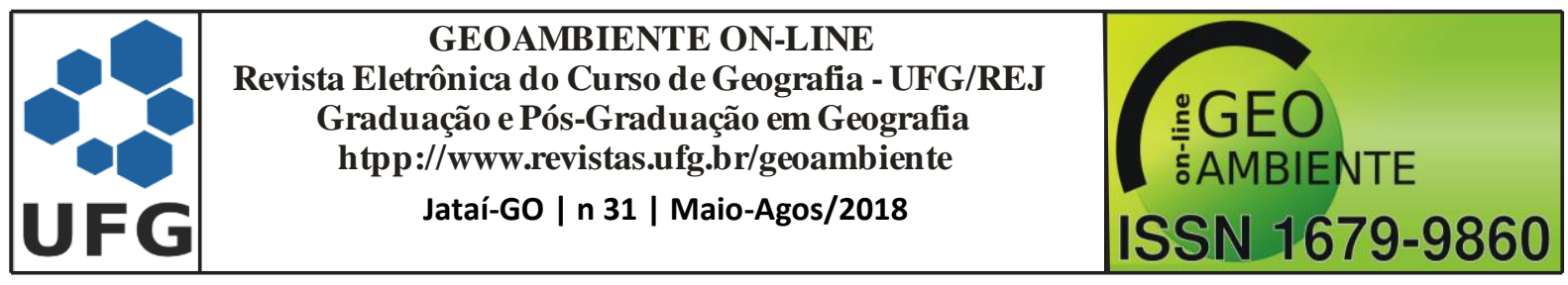

modelo econômico seguido. Logo, buscar a sintropia, no processo produtivo é caminhar rumo a sustentabilidade. Um exemplo disso são os sistemas produtivos agroecoalimentares, como o estudado nesse caso. Estes modelos produtivos apresentam custo entrópico baixíssimo e são capazes de recuperar áreas em processo de degradação, produzir água, solo e alimentos em abundância, devido à interação entre espécies nativas e plantas lenhosas perenes, plantas herbáceas, arbustivas, arbóreas, culturas agrícolas, forrageiras, todos em uma mesma unidade de manejo.

Considera-se que a área estudada é exemplar tanto no manejo do solo e da fauna, quanto na produção de alimentos orgânicos com alta produtividade e de primeira qualidade.

É uma área modelo para formação de agricultores, estudantes, extensionistas e agrônomos, que já recebe a visita de estudantes e agricultores e tem vocação para ser um polo microrregional na produção de alimentos orgânicos, uma vez que não se encontram produtores com este perfil no sudoeste de Goiás. A motivação do agricultor, assim como as características ideais, tanto edáficas, quanto socioeconômicas, permitem que esta experiência seja um sucesso técnico, produtivo, social e ambiental completo.

No entanto o desafio da comercialização está sendo enfrentado, recentemente o agricultor conseguiu a certificação orgânica permitindo o comércio, mas ainda não tem um sistema eficiente de comercialização de seus produtos. Este gargalo tem se demonstrado determinante que já se reflete no plano de manejo da área, na escolha de espécies e de tipos de manejo (diminuição de hortaliças e produtos perecíveis, maior ênfase em madeira, café, cacau, etc.).

Solucionar este gargalo torna-se primordial para a expansão do sistema produtivo, o qual tem vocação para ocupar, no futuro, toda a área da fazenda, o que pode ser o início de um movimento para a transformação da paisagem produtiva e dos sistemas de exploração ambiental e agrícola de toda a microrregião. Uma das pistas a serem exploradas neste sentido é o fortalecimento dos sistemas de comercialização baseados em redes de consumo solidárias, que começam a se organizar em cidades vizinhas.

\section{REFERÊNCIAS}




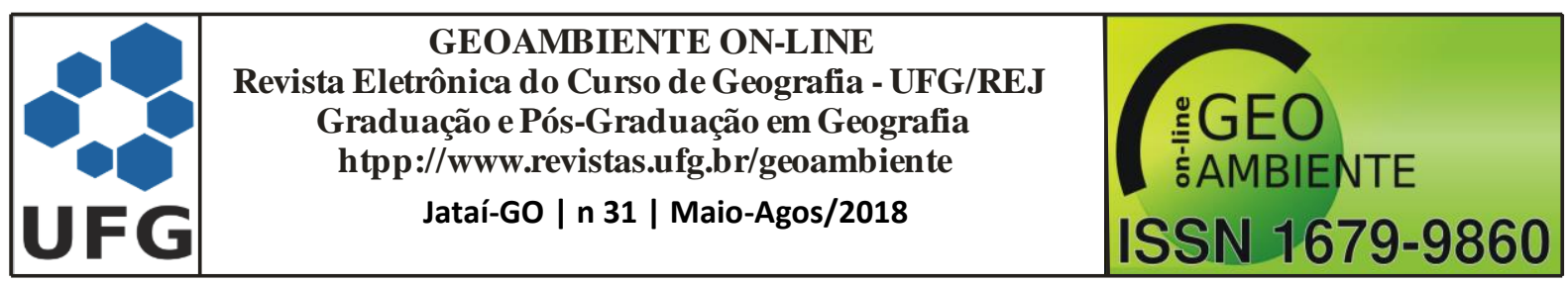

ALBUQUERQUE, U. P. de; LUCENA, R. F. P. de; ALENCAR, N. L. Métodos e técnicas para coleta de dados etnobotânicos. In: ALBUQUERQUE, U. P. de; LUCENA, R. F. P. de; CUNHA, L. V. F. C. da. Métodos e técnicas na pesquisa etnobotânica. 2. ed. Recife: Comunigraf Editora, 2008. p. 41-72.

ALMEIDA, M. V. C.; SOUZA, V. F.; COSTA, R. S. C.; VIEIRA, A. H.; RODRIGUES, A. N. A.; COSTA, J. N. M.; RAM, A.; SÁ, C. P.; VENEZIANO, W.; JUNIOR, R. S. M. Sistemas agroflorestais como alternativa auto-sustentável para o Estado de Rondônia. Porto Velho: PLANAFLORO; PNUD, 1995. 59p.

ALTIERE, Miguel Ángel. Agroecologia: princípios e estratégias para a agricultura sustentável na América Latina do século XXI. In: MOURA, E.G. e AGUIAR, A. C. F. O desenvolvimento rural como forma de aplicação dos direitos no campo: princípios e tecnologias. São Luís: UEMA, 2006. p. 83-99.

ALTIERE, Miguel Ángel. Agroecologia: bases científicas para uma agricultura sustentável. 3. ed. São Paulo, Rio de Janeiro: Expressão Popular, AS-PTA, 2012. 400 p.

GIL, A. C. Como elaborar projetos de pesquisa. 5. ed. São Paulo: Atlas, 2010. 184 p. GODOY, A. S. Pesquisa qualitativa: tipos fundamentais. Revista de Administração de Empresas. São Paulo, v. 35, n.3, p, 20-29. Mai./Jun. 1995.

GOTSCH, E. Homem e natureza: cultura na agricultura. 2. ed. Recife: Centro Sabiá, 1997. Disponível em:

http://media0.agrofloresta.net/static/bibliotecaonline/homemenatureza/homem_e_natureza_go tsch.pdf>. Acesso em 22 mar. 2016.

INSTITUTO BRASILEIRO DE GEOGRAFIA E ESTATÍSTICA. Cidades. Disponível em: <https://cidades.ibge.gov.br/brasil/go/chapadao-do-ceu/panorama>. Acesso em: 25 fev. 2018. LEPSCH, I. Formação e Conservação do Solo. São Paulo: Oficina de Textos, 2002. 177p.

LIMA, J. R. S. Etnobotânica no Cerrado: um estudo no Assentamento Santa Rita, Jataí (GO). Jataí, GO: UFG, 2013. 88 p. Dissertação (Mestrado), Universidade Federal de Goiás, 2013. Disponível em: $\quad<\quad$ https://posgeo.jatai.ufg.br/up/180/o/Dissertac\%C3\%A3o__Jordana_Rezende_Souza_Lima.PDF>.Acesso em: 28 jun. 2016.

MENDONÇA, Francisco de A. Geografia e meio ambiente. 8.ed. São Paulo: Contexto, 2005. $80 p$. 


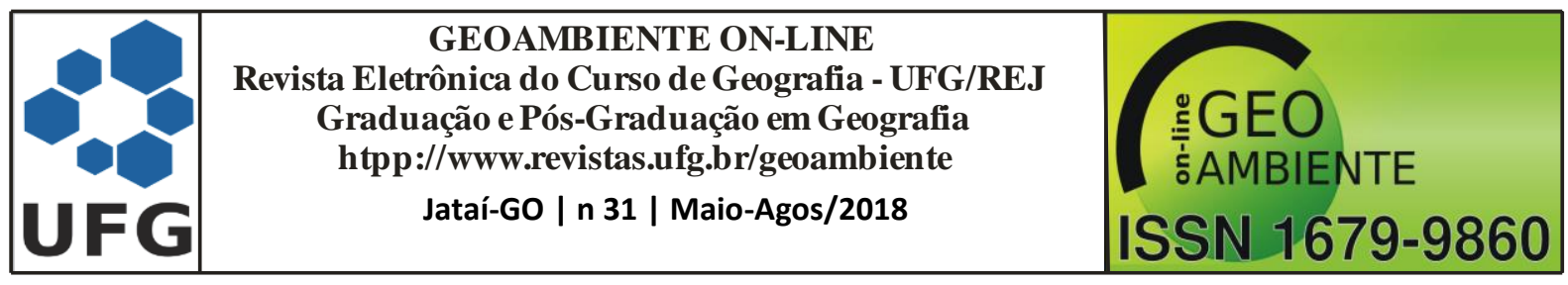

PASSOS, C. A. M.; COUTO, L. Sistemas agroflorestais potenciais para o estado do Mato Grosso do Sul. In: SEMINÁRIO SOBRE SISTEMAS FLORESTAIS PARA O MATO GROSSO DO SUL, 1., 1997, Dourados. Resumos ... Dourados: Embrapa-CPAO, 1997. p. 1622. (Embrapa-CPAO. Documentos, 10).

PAULA, M. C. de; OLIVEIRA, R. M. de; RIBEIRO, D. D. Experiências de avaliação de aspectos subjetivos em processo educativo de jovens agricultores assentados em Jataí-GO. In: ENCONTRO NACIONAL DE GEOGRAFIA AGRÁRIA, 21., 2012, Uberlândia. Anais... Uberlândia: UFU, 2012.

PETERSEM, Paulo. Prefácio. In: ANA (Articulação Nacional de Agroecologia). Olhares agroecológicos: análise econômico-ecológica de agroecossistemas em sete territórios brasileiros. Rio de Janeiro: ANA, 2017. p. 7-15.

SANTOS, M. J. C. Avaliação econômica de quatro modelos agroflorestais em áreas degradadas por pastagens na Amazônia Ocidental. 2000. 75p. Dissertação (Mestrado) Escola Superior de Agricultura “Luiz de Queiroz”, Universidade de São Paulo, Piracicaba. Disponível em: <http://www.teses.usp.br/teses/disponiveis/11/11142/tde-08112002-134456 /publico/mario.pdf>. Acesso em: 28 jun. 2016.

SEABRA, G. de F. Pesquisa científica: o método em questão. Brasília: Editora UnB, 2011. SILVA, Lilian Leandra. O papel do estado no processo de ocupação das áreas de cerrado entre as décadas de 60 e 80. Caminhos de Geografia, vol. 1, n. 2, dez/2000. p. 24-36.

TOLEDO, Víctor. M. BARRERA-BASSOLS, Narciso. A memória biocultural: a importância ecológica das sabedorias tradicionais. Tradução de Rosa L. Peralta. São Paulo: Expressão Popular, 2015. $272 \mathrm{p}$.

YOUNG, A. Agroforestry for soil management. 2.ed. Wallingford: ICRAF and CAB International, 1997. 320 p. 